\title{
Hybrid Oncocitic/Chromophobe Renal Cell Carcinoma
}

\author{
Gawlik-jakubczak T* and Matuszewski M \\ Department of Urology, Medical University of Gdansk, Poland
}

\begin{abstract}
The hybrid oncocytic and chromophobe renal cell tumour is rare kidney cancer. We describe a case of HOCRCT in 64-yearsold woman with incidentally found tumour limited to the kidney. Radical nephrectomy was performed, no complication occurred in postoperative period. Final pathology result showed HOCRCT. During almost 5 years of observation there is no symptoms of recurrence.
\end{abstract}

Keywords: Hybrid oncocytic; Chromophobe renal cell carcinoma; Pathology

\section{Introduction}

First described in 2002 renal hybrid tumours constitute a rare type of kidney neoplasm. The term "hybrid oncocytic and chromophobe tumour "HOCT was absent in 2004 WHO classification of renal tumours. The true incidence of this malignancy is still unknown, and its clinical outcome rather benign. Only few authors have reported clinical characteristics of renal HOCT thus far [1-5]. They are typically diagnosed in patients with Birth-Hogg-Dube (BHD) syndrome and rarely found as a sporadic malignancy $[1,2]$. These tumours are defined as tumours having a mixture of cells with the morphological features observed in chromophobe RCC and oncocytoma. To establish clinical features of HOCRC in same medical centres all pathological samples with kidney oncocytomas and chromophobe cancer was reviewed.

\section{Case Description}

A 64-year old woman with tumor of right kidney was admitted to our clinic in December 2013. The tumour $(38 \times 29 \mathrm{~mm})$ was found on routine ultrasound of abdomen and confirmed on computed tomography. Lesion was in central part of kidney and showed evident contrast enhancement. Creatinine level was $0.87 \mathrm{mg} / \mathrm{dl}$. The patient was treated for mild hypertension for 10 years. No cutaneous lesion was observed. Due to the unfavourable location of the tumor the patient was qualified to radical open nephrectomy. No complication occurred after surgery. The perioperative period was uneventful, and the patient was discharged home on postoperative day 5. Pathology report described solitary yellowish tumour in central part limited to the right kidneypT1N0M0. Microscope image showed hybrid chromophobe, oncocytic renal cell carcinoma, without tumor necrosis and vascular invasion. No evidence of recurrence or spread of neoplasm has been found on control visits scheduled every 6 months till 2018 (Figures 1A-1D).

\section{Discussion}

The incidence of sporadic hybrid tumor is estimated at $1 \%$ [1]. On ultrasonography a chromophobe RCCs usually appears as hyperechoic lesion with homogenous enhancement. Oncocytomas usually are more heterogenous with central scar and typical spoke wheel-like arterial pattern. Central scar is not specific for renal oncocytomas and can be also found in about $27 \%$ of HOCTs [6]. Usually macroscopically the tumors are round, firm, solid and well demarcated from surrounding tissues, yellowish to tan in colour without haemorrhage. Architecture of tumor is mainly solid alveolar or ductal [4]. Renal HOCTs shows an admixture of areas of typical for chromophobe renal cell carcinoma and areas of oncocytoma. Typically mosaic of oncocytes and chromophobe like-cells are characteristic and chromophobe cells present from 20 till $80 \%$ of tumor. Tumors are composed from large eosinophilic cells with central nuclei or cells with hybrid features i.e. oncocytic cytoplasm and

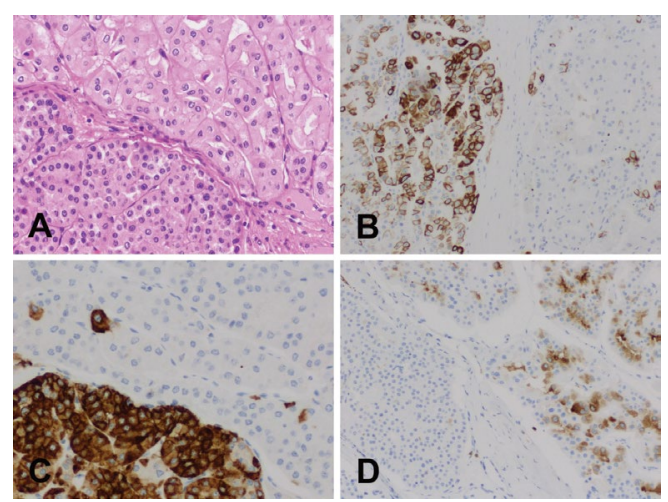

Figure 1: (A) The tumor shows a biphasic morphology that resembling oncocytoma (lower left) and chromophobe cell carcinoma (upper right corner). They differ in expression of cytokeratin 7 (B), CD15 (C) and CD10 (D).

irregular nuclei or clarified chromophobe-like cytoplasm and round regular nuclei.

On Hale's staining most cells show apical pattern, rare diffuse pattern. $15-100 \%$ of the cells stains positively for Cytokeratin 7 [4].

Hybrid tumors can occur as sporadic or in Birt-Hogg-Dube syndrome or in oncocytosis. BHD syndrome is congenital abnormalities, autosomal dominant geno-dermatosis with increased risk of developing renal cell carcinoma, pulmonary cysts and pneumothorax. Patients with BHD syndrome has benign skin lesions: white papules -fibrofolliculomas. BHD is dominantly inherited. mutations in the folliculin gene FLCN. RCC can occur in $34 \%$ of patients with DHB. Chromophobe RCC and oncocytoma probably both arises from A and $B$ intercalated cells of renal collecting tubules so hybrid tumors could be the form between them.

\section{Conclusion}

Modern pathology can differentiate chromophobe oncocytic hybrid RCC from other type of renal cancers like pure oncocytomas or

*Corresponding author: Gawlik-jakubczak T, Department of Urology, Medical University of Gdansk, Poland, Tel: +48603467965; E-mail: teresaj@gumed.edu.pl

Received October 29, 2018; Accepted October 30, 2018; Published October 31, 2018

Citation: Gawlik-jakubczak T, Matuszewski M (2018) Hybrid Oncocitic/ Chromophobe Renal Cell Carcinoma. J Clin Case Rep 8: 1186. doi: 10.4172/21657920.10001186

Copyright: (C) 2018 Gawlik-jakubczak T, et al. This is an open-access article distributed under the terms of the Creative Commons Attribution License, which permits unrestricted use, distribution, and reproduction in any medium, provided the original author and source are credited. 
Citation: Gawlik-jakubczak T, Matuszewski M (2018) Hybrid Oncocitic/Chromophobe Renal Cell Carcinoma. J Clin Case Rep 8: 1186. doi: 10.4172/2165-7920.10001186

Page 2 of 2

chromophobe cancers. Modern radiology is able to detect small and asymptomatic tumours. Clinical course of COHRCC is still unclear but data from few published case reports suggest that the prognosis is relatively good up to $100 \%$ survival rates [2]. Proper pathology classification of tumour helps in planning further control. However, observation of a larger group of patients is needed to unequivocally conclude on the prognosis in renal HOCT.

\section{References}

1. Mai KT, Dhamanaskar E, Stinson BW (2005) Hybrid chromophobe renal cell carcinoma. Pathology Research and Practice 201: 385-389.

2. Delongchamps N, Galmiche L, Eiss YR, Vogt B, Timsit M, et al. (2009) Hybrid tumour oncocytoma-chromophobe renal cell carcinoma of the kidney: A report of seven sporadic cases. BJUI 103: 1381-1384.
3. Petersson F, Gatalica Z, Grossmann P, Montiel M, Cabrero I, et al (2010) Sporadic hybrid oncocytic/chromophobe tumor of the kidney: A clinicopathologic, histomorphologic, immunohistochemical ultrastructural and molecular cytogenetic study of 14 cases. Virchows Arch 456: 355-365.

4. Shin M, Park S, Lee J, Park H, Chang I, et al. (2014) Unilateral renal oncocytosis and combined hybrid tumor: A case report and review of literature. Jpn J Radiol 32: $556-560$.

5. Waldert M, Klatte T, Haitel A, Ozsoy M, Schmidbauer J, et al. (2010) Hybrid renal cell carcinomas containing histopathologic features of chromophobe renal cell carcinomas and oncocytomas have excellent oncologic outcomes. Eur Urol 57: 661-666.

6. Pote N, Vieillefond A, Couturier J, Arrufat S, Metzger I, et al. (2013) Hybrid oncocytic/chromophobe renal cell tumours do not display genomic features of chromophobe renal cell carcinomas. Virchow Arch 462: 633-638. 